\title{
New antiepileptic drugs: a systematic review of their efficacy and tolerability
}

\author{
A G Marson, Z A Kadir, D W Chadwick
}

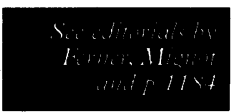

\section{Abstract}

Objectives-To evaluate the efficacy and tolerability of the newly developed antiepileptic drugs gabapentin, lamotrigine, tiagabine, topiramate, vigabatrin, and zonisamide in patients with refractory partial epilepsy.

Design-Systematic review of published and unpublished randomised controlled trials of add-on treatment with new antiepileptic drugs.

Subjects-20 published and eight unpublished trials representing 3883 patients with refractory partial epilepsy.

Main outcome measures-Proportion of patients who $(a)$ showed $50 \%$ or greater reduction in frequency of seizures ( $50 \%$ responders) and $(b)$ withdrew from each study for any reason.

Results-Odds ratios $(95 \%$ confidence intervals) relative to placebo for $50 \%$ responders were 2.29 (1.53 to 3.43) for gabapentin, 2.32 (1.47 to 3.68) for lamotrigine, 3.03 (2.01 to 4.58 ) for tiagabine, 4.22 (2.80 to 6.35) for topiramate, 3.68 (2.45 to 5.51) for vigabatrin, and 2.47 (1.36 to 4.47 ) for zonisamide. Odds ratios for withdrawal were 1.36 (0.75 to 2.49) for gabapentin, 1.19 (0.79 to 1.79) for lamotrigine, 1.81 (1.21 to 2.70) for tiagabine, 2.42 (1.43 to 4.11) for topiramate, 2.58 (1.26 to 5.27) for vigabatrin, and 5.70 (1.76 to 18.49$)$ for zonisamide. Comparing results for each drug showed that all of the $95 \%$ confidence intervals overlapped, indicating that they were not significantly different in terms of efficacy and tolerability.

Conclusions-All six drugs were significantly better than placebo at reducing frequency of seizures. These results do not allow an evidence based choice between these drugs as we have no conclusive indication of differences in efficacy or tolerability.

\section{Introduction}

Most patients with epilepsy have a good prognosis and their seizures will be controlled by treatment with a single antiepileptic drug, ${ }^{1}$ but up to $30 \%$ develop refractory epilepsy ${ }^{2}$ that often requires treatment with combinations of antiepileptic drugs. These cases represent a considerable therapeutic problem since up to $2-3 \%$ of the population will suffer from epilepsy at some time in their lives. ${ }^{3}$

Over the past decade there has been renewed interest in the development of new antiepileptic drugs as the standard drugs clearly do not control all patients' seizures and they are not without side effects. In the first instance new antiepileptic drugs are tested in patients with refractory partial epilepsy as add-on treatment in randomised placebo controlled trials. After this they are usually compared with standard treatments in monotherapy studies, predominantly in patients with a new diagnosis of epilepsy. Ideally, any choice made between antiepileptic drugs should be based upon the results of comparative randomised controlled trials. At present

there is insufficient evidence to guide a choice between standard treatments such as carbamazepine, phenytoin, and valproate. ${ }^{4}$ The place of new treatments is even more uncertain, as there have been few monotherapy studies comparing new antiepileptic drugs with standard treatments and there have been no studies comparing one new drug with another, whether given as monotherapy or add-on treatment. Nevertheless, doctors are faced with an increasing choice of new antiepileptic drugs to prescribe to refractory patients.

In order to address this problem, we undertook a systematic review of published and unpublished randomised controlled trials in which gabapentin, lamotrigine, tiagabine, topiramate, vigabatrin, and zonisamide were compared with placebo as add-on treatments in patients with drug resistant partial epilepsy. The populations in these studies are representative of the majority of patients with refractory epilepsy. Our review generated overall estimates of the efficacy and tolerability of each drug compared with placebo. As the methodologies used and the patients recruited were similar in these studies, these overall estimates could be compared between drugs, allowing a broad estimate of their comparative efficacy and tolerability. Although this is an indirect comparison that requires cautious interpretation, it provides the best comparative data available on these drugs to date (though in no way replacing randomised controlled studies comparing active treatments). A systematic approach and statistical synthesis of available data seems least "bad" at this time and a better approach than reliance on the views of "opinion leaders."

\section{Methods}

TRIALS

We found reports of published and unpublished randomised controlled trials by searching our database of epilepsy randomised controlled trials and by contacting the relevant drug companies. The randomised controlled trials on our database were found by searching Medline from 1966 to 1995 and by searching journals by hand. ${ }^{5}$

Trials were included if $(a)$ they were randomised, placebo controlled trials investigating add-on treatment with gabapentin, lamotrigine, tiagabine, topiramate, vigabatrin, or zonisamide; (b) they recruited only patients with partial epilepsy; $(c)$ they were parallel studies or crossover studies for which data could be acquired (to allow the first treatment period to be treated as a parallel trial); (d) treatment was continued for at least eight weeks; and (e) seizures were reported as an outcome. Trials were excluded if they used a response conditional design ${ }^{6}$ - that is, trials in which patients are allocated treatment only if they showed a predetermined response to treatment during a baseline period before randomisation.

\section{OUTCOME MEASURES}

The outcome we chose as a measure of efficacy was the number of patients with a $50 \%$ reduction in the 


\begin{tabular}{|c|c|c|c|c|c|}
\hline \multirow[b]{2}{*}{ Trial } & \multirow[b]{2}{*}{$\begin{array}{c}\text { Study design } \\
\text { (weeks of } \\
\text { treatment) }\end{array}$} & \multirow[b]{2}{*}{$\begin{array}{c}\text { Daily treatment } \\
\text { (No of subjects allocated) }\end{array}$} & \multicolumn{3}{|c|}{ Subjects } \\
\hline & & & Male: female & Age range (years) & $\begin{array}{l}\text { No of other } \\
\text { antleplleptlc drugs } \\
\text { used }\end{array}$ \\
\hline \multicolumn{6}{|l|}{ Gabapentin } \\
\hline Anhut et $a l^{9}$ & Parallel (12) & 900 mg (111), 1200 mg (52), placebo (109) & 154:120 & $12-67$ & $\leqslant 2$ \\
\hline Sivenius et a $f^{0}$ & Parallel (12) & $900 \mathrm{mg}(18), 1200 \mathrm{mg}(9)$, placebo (18) & $20: 23$ & $16-59$ & $\leqslant 2$ \\
\hline $\begin{array}{l}\text { UK Gabapentin Study } \\
\text { Group }^{11}\end{array}$ & Parallel (14) & $1200 \mathrm{mg}(61)$, placebo (66) & $53: 74$ & $14-73$ & $\leqslant 2$ \\
\hline $\begin{array}{l}\text { US Gabapentin Study } \\
\text { Group }^{12}\end{array}$ & Parallel (12) & $\begin{array}{c}600 \mathrm{mg}(53), 1200 \mathrm{mg}(101), 1800 \mathrm{mg}(54), \\
\text { placebo (98) }\end{array}$ & 202:104 & $16-70$ & $\leqslant 2$ \\
\hline \multicolumn{6}{|l|}{ Lamotrigine } \\
\hline Binnie $\theta t a l^{14}$ & Crossover (12) & Median 20 mg (16), placebo (18) & $22: 8$ & $16-51$ & $\leqslant 4$ \\
\hline $\begin{array}{l}\text { Denmark UK46 } \\
\text { (unpublished) }\end{array}$ & Crossover (12) & Median $300 \mathrm{mg}$ (30), placebo (26) & $27: 29$ & $18-67$ & $\leqslant 3$ \\
\hline Jawad et al ${ }^{15}$ & Crossover (12) & Median $250 \mathrm{mg}$ (12), placebo (12) & $12: 9$ & $19-65$ & $\leqslant 2$ \\
\hline Loiseau et al ${ }^{16}$ & Crossover (8) & Median $300 \mathrm{mg}$ (11), placebo (14) & $11: 12$ & $19-65$ & $\leqslant 2$ \\
\hline Matsuo ot $a l^{13}$ & Parallel (24) & $300 \mathrm{mg}(71), 500 \mathrm{mg}$ (72), placebo (73) & $67: 149$ & $18-63$ & $\leqslant 3$ \\
\hline Messenheimer et al ${ }^{17}$ & Crossover (14) & Median $400 \mathrm{mg}$ (46), placebo (52) & $46: 52$ & $18-64$ & $\leqslant 3$ \\
\hline Schapel et a $\left.\right|^{18}$ & Crossover (12) & Median $300 \mathrm{mg}$ (20), placebo (21) & $21: 20$ & $17-63$ & $\leqslant 2$ \\
\hline Smith $e t a l^{19}$ & Crossover (12) & Median $300 \mathrm{mg}$ (11), placebo (12) & $11: 12$ & $16-62$ & $\leqslant 2$ \\
\hline $\begin{array}{l}\text { Munich UK } 18 \\
\quad \text { (unpublished) }\end{array}$ & Crossover (18) & Median $300 \mathrm{mg}$ (41), placebo (40) & $33: 48$ & $15-67$ & $\leqslant 2$ \\
\hline \multicolumn{5}{|l|}{ Tlagabine } & $\leqslant 2$ \\
\hline TIA-106 (unpublished) & Parallel (16) & $16 \mathrm{mg} \mathrm{(61),} 32 \mathrm{mg}(88), 56 \mathrm{mg}(57)$ & 272:127 & $12-77$ & $\leqslant 3$ \\
\hline TIA-107 (unpublished) & Parallel (22) & $32 \mathrm{mg}(77)$, placebo (77) & $89: 65$ & $18-71$ & $\leqslant 3$ \\
\hline TIA-109 (unpublished) & Parallel (12) & $32 \mathrm{mg}(210)$, placebo (108) & $178: 140$ & $12-71$ & $\leqslant 3$ \\
\hline \multicolumn{6}{|l|}{ Topiramate } \\
\hline $\begin{array}{l}\text { Europe Y1 } \\
\text { (unpublished) }\end{array}$ & Parallel (11) & $400 \mathrm{mg}$ (23), placebo (24) & 21:21 & $5-63$ & $\leqslant 2$ \\
\hline Tassinari $\theta t a l^{20}$ & Parallel (12) & $600 \mathrm{mg}(30)$, placebo (30) & $24: 6$ & $18-65$ & $\leqslant 2$ \\
\hline Ben-Menachem et $a l^{21}$ & Parallel (13) & $800 \mathrm{mg} \mathrm{(28),} \mathrm{placebo} \mathrm{(28)}$ & $23: 5$ & $19-63$ & $\leqslant 2$ \\
\hline Faught $e t a l^{22}$ & Parallel (16) & $\begin{array}{c}200 \mathrm{mg} \mathrm{(45),}, 400 \mathrm{mg} \mathrm{(45),}, 600 \mathrm{mg} \mathrm{(46),} \\
\text { placebo (45) }\end{array}$ & 143:38 & $19-68$ & $\leqslant 2$ \\
\hline Privitera $\theta t a l^{23}$ & Parallel (18) & 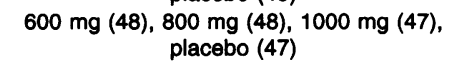 & 152:38 & $18-68$ & $\leqslant 2$ \\
\hline \multicolumn{6}{|c|}{ 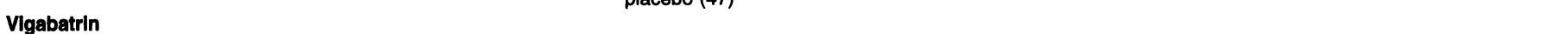 } \\
\hline French $\theta t a l^{24}$ & Parallel (12) & 3000 mg (93), placebo (90) & $80: 102$ & $18-60$ & $\leqslant 2$ \\
\hline Grunewald et $a l^{25}$ & Parallel (20) & 3000 mg (22), placebo (23) & 24:21 & $15-61$ & $\leqslant 3$ \\
\hline AUS01 (unpublished) & Crossover (8) & $2000 \mathrm{mg}$ (25), $3000 \mathrm{mg}$ (23), placebo (45) & $42: 51$ & $17-64$ & $\leqslant 3$ \\
\hline Penry et $a l^{26}$ & Parallel (18) & 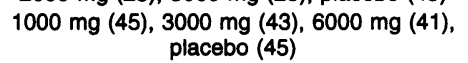 & $83: 91$ & $18-63$ & $\leqslant 3$ \\
\hline \multicolumn{6}{|l|}{ Zonisamide } \\
\hline Schmidt $\theta t$ al ${ }^{27}$ & Parallel (12) & Mean $500 \mathrm{mg}(71)$, placebo (68) & $81: 58$ & $18-59$ & $\leqslant 3$ \\
\hline Wilder et $a l^{28}$ & Parallel (12) & Mean $500 \mathrm{mg}$ (78), placebo (74) & $101: 51$ & $17-67$ & $\leqslant 2$ \\
\hline
\end{tabular}

frequency of seizures compared with baseline $(50 \%$ responders). This refers to partial seizures of any type (simple partial, complex partial, secondary generalising tonic-clonic seizures). We chose this outcome because it was commonly reported in this type of study, it could be calculated for studies that did not report this outcome provided the frequency of seizures at baseline were recorded, and it is a dichotomous variable allowing the calculation of odds ratios. We recorded the numbers of patients withdrawing after randomisation (for any reason) as a global measure of the overall tolerability of the antiepileptic drugs. ${ }^{7}$

AGM and ZAK extracted data on intention to treat for all patients randomised to treatment from each trial report. Results were compared, and any disagreements were resolved at conference. If reports contained insufficient information the relevant drug companies were contacted for additional data.

\section{STATISTICAL ANALYSIS}

Odds ratios with $95 \%$ confidence intervals were generated for each outcome in each trial. Odds ratios of $>1$ indicate that an event is more likely to occur in the group receiving active treatment than in the group receiving placebo. Heterogeneity between trials was tested by means of a $\chi^{2}$ test, and $P \leqslant 0.05$ was considered to indicate significant heterogeneity. Provided no significant heterogeneity was found, summary odds ratios (95\% confidence intervals) were calculated using a fixed effects model. ${ }^{8}$ In addition, we undertook a random effects analysis, investigated dose-response rela- tions using regression analyses, and calculated odds ratios for side effects with each drug, but these results are outside the scope of this article and will be reported separately.

\section{Results}

We found a total of 20 published and eight unpublished trials which met our inclusion and exclusion criteria and which represented 3883 patients randomised to treatment. ${ }^{9-28}$ All of these studies were included in our meta-analysis. All the studies used allocation of sequentially numbered packages as a method of concealment of randomisation, and all were double blind. Table 1 shows the other characteristics of these studies. For the purpose of this review, trials which had been published only as abstracts and not full reports were considered unpublished.

EFFICACY ( $50 \%$ RESPONDERS)

We detected no significant heterogeneity between trials with respect to the proportion of patients who showed a $50 \%$ reduction in the frequency of seizures ( $50 \%$ responders) for any of the six drugs (Figs 1-6).

Gabapentin-We found four parallel studies in which supplementary gabapentin was compared with placebo..$^{9-12}$ These studies tested doses of 600,900 , 1200 , and $1800 \mathrm{mg}$ gabapentin a day and included a total of 750 patients. The overall odds ratio ( $95 \%$ confidence interval) for $50 \%$ responders across all studies was 2.29 (1.53 to 3.43 ) (fig 1). The summary odds 
ratios for each dose indicated increasing efficacy with increasing doses, with no suggestion of a plateauing of effect at the doses used in these studies.

Lamotrigine-We found one published ${ }^{13}$ and one unpublished (US16, Glaxo Wellcome) parallel study and six published ${ }^{14-19}$ and two unpublished (UK 18 and UK 46, Glaxo Wellcome) crossover studies in which

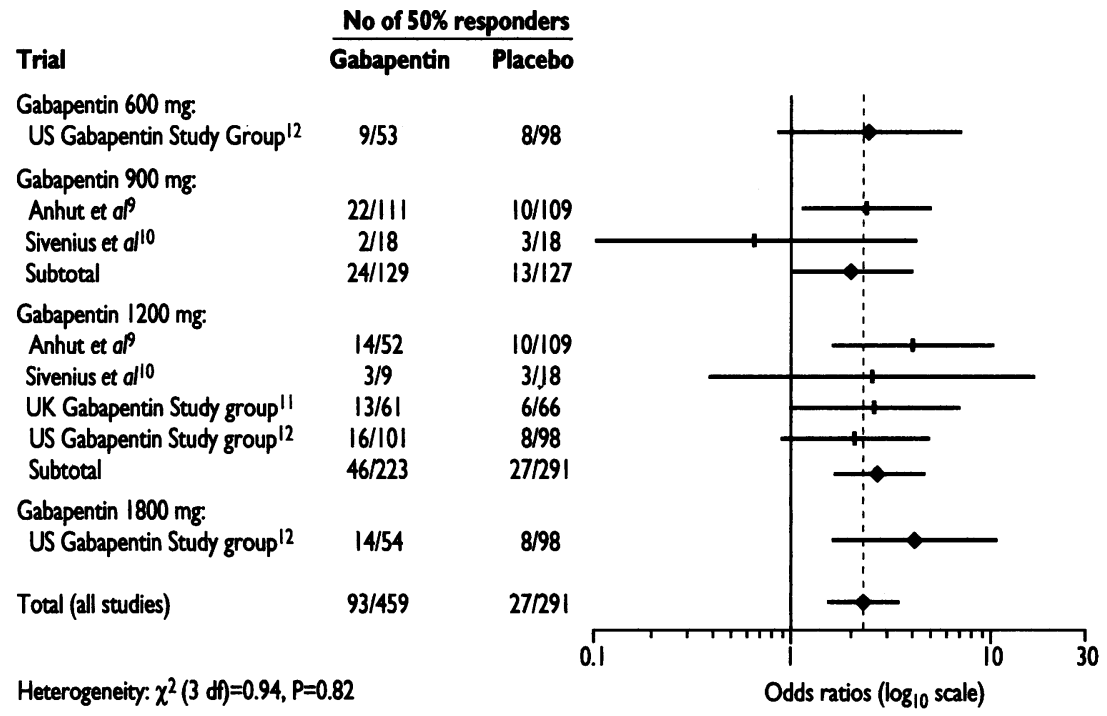

Fig 1 -Odds ratios (95\% confidence intervals) for proportion of patients who showed $50 \%$ reduction in frequency of seizures (50\% responders) after add-on treatment with gabapentin

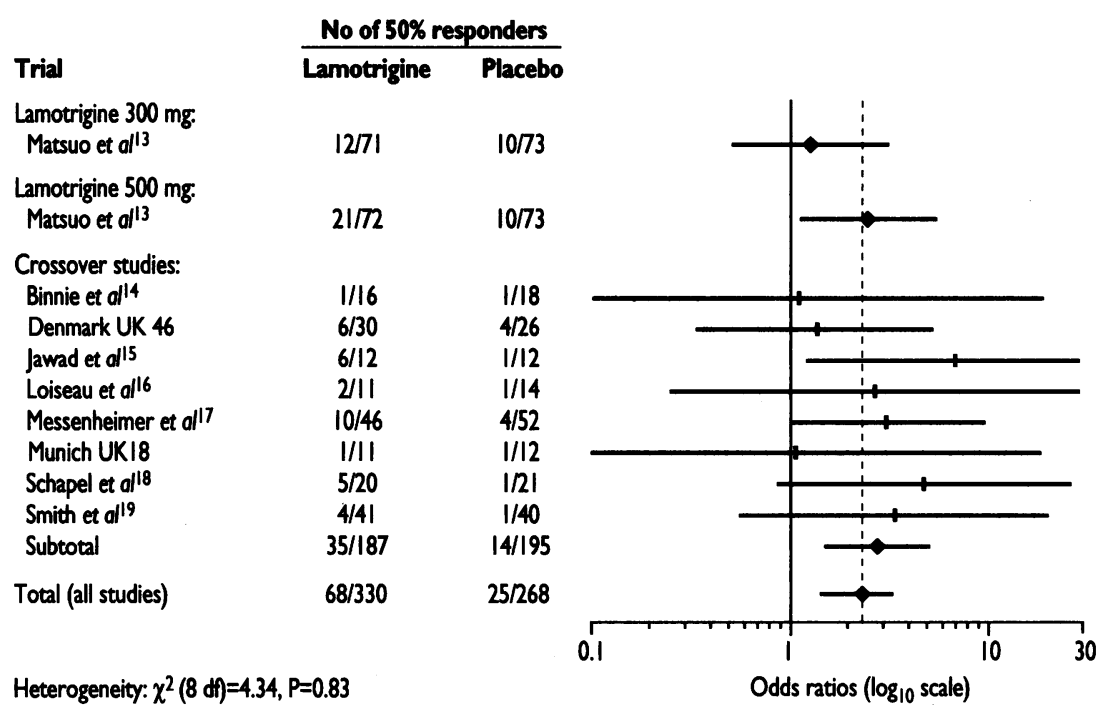

Fig 2 -Odds ratios (95\% confidence intervals) for proportion of patients who showed $50 \%$ reduction in frequency of seizures (50\% responders) after add-on treatment with lamotrigine

\begin{tabular}{|c|c|c|c|c|}
\hline \multirow[b]{2}{*}{ Trial } & \multicolumn{2}{|c|}{ No of $50 \%$ responders } & & \\
\hline & Tiagabine & Placebo & & \\
\hline \multicolumn{5}{|l|}{ Tiagabine $16 \mathrm{mg}$. } \\
\hline \multicolumn{5}{|c|}{ Tiagabine $30-32 \mathrm{mg}$. } \\
\hline TIA-106 & $17 / 88$ & $4 / 91$ & & \\
\hline TIA-107 & $11 / 77$ & $5 / 77$ & & 7 \\
\hline TIAI09 & $53 / 210$ & $8 / 108$ & & \\
\hline Subtotal & $81 / 375$ & $17 / 276$ & & \\
\hline \multicolumn{5}{|l|}{ Tiagabine $56 \mathrm{mg}$. } \\
\hline TIA-106 & $17 / 57$ & $4 / 91$ & & \\
\hline \multirow[t]{2}{*}{ Total (all studies) } & $104 / 493$ & $17 / 276$ & & $\longrightarrow$ \\
\hline & & & कानाना & Tामाणा \\
\hline \multirow{2}{*}{\multicolumn{3}{|c|}{ Heterogeneity: $\chi^{2}(2 d f)=0.33, P=0.85$}} & 0.1 & 10 \\
\hline & & & Odds & ratios ( $\log _{10}$ scale) \\
\hline
\end{tabular}

Fig 3-Odds ratios (95\% confidence intervals) for proportion of patients who showed $50 \%$ reduction in frequency of seizures (50\% responders) after add-on treatment with tiagabine supplementary lamotrigine was compared with placebo. One parallel study tested doses of $300 \mathrm{mg}$ and $500 \mathrm{mg}$ lamotrigine a day, ${ }^{13}$ while the US 16 study tested a range of doses up to $500 \mathrm{mg}$ a day. The median daily doses in the crossover studies ranged from $200 \mathrm{mg}$ to $400 \mathrm{mg}$ a day. Numbers of seizures at baseline were not recorded in the US16 study, and it is therefore not possible to calculate the numbers of $50 \%$ responders. This study contributed only to the withdrawal analysis. In total these studies included 1044 patients. The overall odds ratio for $50 \%$ responders across all studies was 2.32 (1.47 to 3.68 ) (fig 2).

Tiagabine-We found three unpublished parallel studies (TIA-106, TIA-107, and TIA-109, Novo Nordisk) in which supplementary tiagabine was compared with placebo. Doses of $16,30,32$, and $56 \mathrm{mg}$ tiagabine a day were tested. In total these studies included 769 patients. The overall odds ratio for $50 \%$ responders across all studies was 3.03 (2.01 to 4.58 ) (fig 3 ). The summary odds ratios for each dose indicated increasing efficacy with increasing doses, with no suggestion of a plateauing of effect at the doses used in these studies.

Topiramate - We found four published ${ }^{20-23}$ and one unpublished (Europe Y1, Janssen Cilag) parallel studies in which supplementary topiramate was compared with placebo. These studies tested doses of $200,400,600$, 800 , and $1000 \mathrm{mg}$ a day. In total these five studies included 534 patients. The overall odds ratio for $50 \%$ responders across all studies was 4.22 (2.80 to 6.35) (fig 4). The summary odds ratios for each dose indicated a plateauing of therapeutic effect with doses over $600 \mathrm{mg}$ a day.

Vigabatrin -We found one unpublished crossover study (AUS01, Hoechst Marrion Roussel) and three published parallel studies ${ }^{24-26}$ in which doses of 1000 , 2000,3000 , and $6000 \mathrm{mg}$ vigabatrin a day were tested. These studies included a total of 495 patients. Vigabatrin has also been tested in a number of crossover studies, but these studies did not restrict their inclusion criteria to partial epilepsy and hence were excluded from this overview. The overall odds ratio for $50 \%$ responders across all studies was 3.68 (2.45 to 5.51) (fig 5). The summary odds ratios for each dose indicated increasing efficacy with increasing doses. There was no clear indication of a plateauing of effect, but doses between $3000 \mathrm{mg}$ and $6000 \mathrm{mg}$ a day were not tested.

Zonisamide-We found two parallel studies ${ }^{27} 28$ in which supplementary zonisamide was compared with placebo. Both of these studies tested median doses of $500 \mathrm{mg}$ a day. In total these studies included 291 patients. The overall odds ratio for $50 \%$ responders was 2.47 (1.36 to 4.47 ) (fig 6).

Comparison of efficacy of drugs-When we compared the overall estimates of odds ratios for $50 \%$ responders with each drug we found that all of the $95 \%$ confidence intervals overlapped. Thus, we have no conclusive evidence of a difference in efficacy between these drugs when proportions of patients who showed a $50 \%$ reduction in the frequency of seizures are used as an outcome. Despite this, the drug that was apparently most effective (topiramate) may have been almost twice as effective as the one apparently least effective (gabapentin).

\section{WITHDRAWAL FROM TREATMENT}

Figure 7 shows the odds ratios $(95 \%$ confidence intervals) for withdrawal from treatment for any reason. The summary estimates for gabapentin (1.36 (0.75 to $2.49)$ ) and lamotrigine (1.19 (0.79 to 1.79$)$ ) have $95 \%$ confidence intervals that span unity, indicating that we have no conclusive evidence that patients were more likely to withdraw from taking these drugs than from taking placebo. The summary estimates for tiagabine (1.81 (1.21 to 2.70$)$ ), topiramate $(2.42(1.43$ to 4.11$)$ ), 
vigabatrin (2.58 (1.26 to 5.27)), and zonisamide (5.70 (1.76 to 18.49)) each have a lower $95 \%$ confidence interval greater than unity, indicating that patients were significantly more likely to have withdrawn from taking these drugs than from taking placebo.

When we compared the overall estimates of odds ratios for withdrawal for any reason we again found that the $95 \%$ confidence intervals overlapped, indicating that we have no conclusive evidence of a difference between these drugs. Despite this, the treatment which seemed most likely to cause withdrawal from treatment (zonisamide) may have been more than four times as

\section{Topiramate}

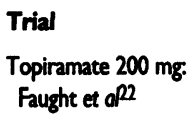

Faught et of2

Topiramate $400 \mathrm{mg}$.

Europe YI

Faught et ap2

Subtotal

Topiramate $600 \mathrm{mg}$ :

Tassinari et apo

Faught et ap2

Privitera et of3

Subtotal

Topiramate $800 \mathrm{mg}$.

Ben-Menachem et of

Privitera et oR3

Subtotal

Topiramate $1000 \mathrm{mg}$.

Privitera et ap3

Total (all studies)

Heterogeneity: $\chi^{2}(4 \mathrm{dt}=4.77, P=0.31$
$12 / 45$

$8 / 23$

$21 / 45$

29168

$14 / 30$

$21 / 46$

$21 / 48$

$56 / 124$

$12 / 28$

$19 / 48$

$31 / 76$

$18 / 47$

$146 / 360$

Fig 4 - Odds ratios (95\% confidence intervals) for proportion of patients who showed $50 \%$ reduction in frequency of seizures (50\% responders) after add-on treatment with topiramate

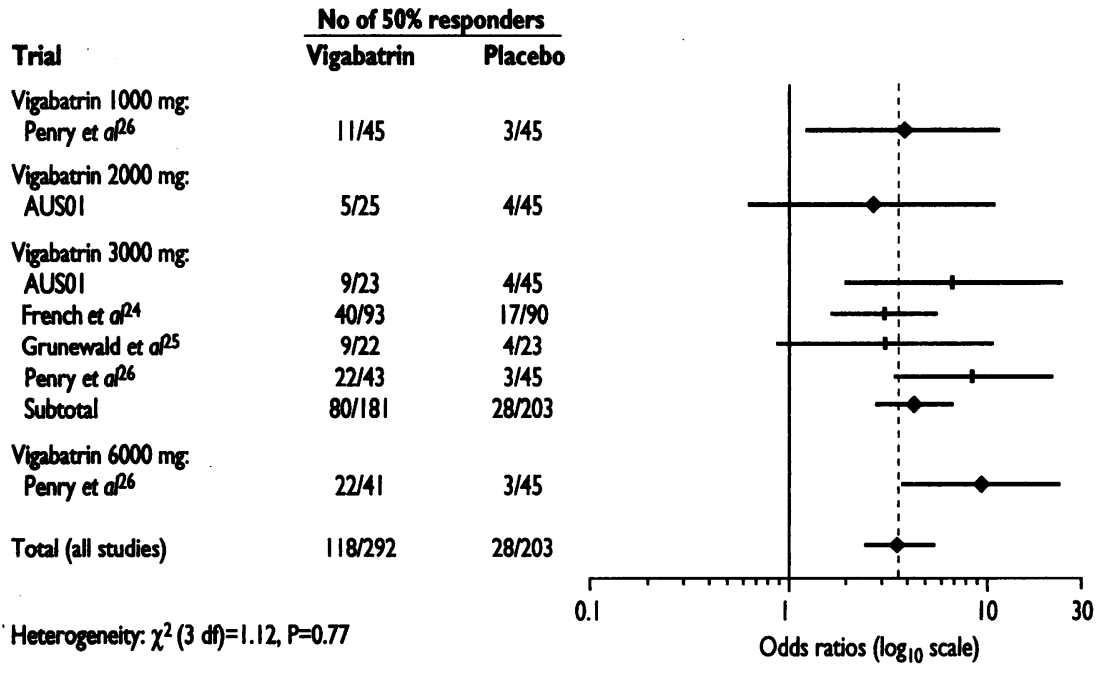

Fig 5-Odds ratios (95\% confidence intervals) for proportion of patients who showed 50\% reduction in frequency of seizures (50\% responders) after add-on treatment with vigabatrin

\section{Trial}

Median $500 \mathrm{mg}$.

Schmidt et ap?

Wilder et aps

Total

$\frac{\text { No of } 50 \% \text { responders }}{\text { Zonisamide Placebo }}$

Heterogeneity: $\chi^{2}(1 d i)=1.33, P=0.25$
$37 / 149$

20/71

17778

$6 / 68$

$10 / 74$

$16 / 142$

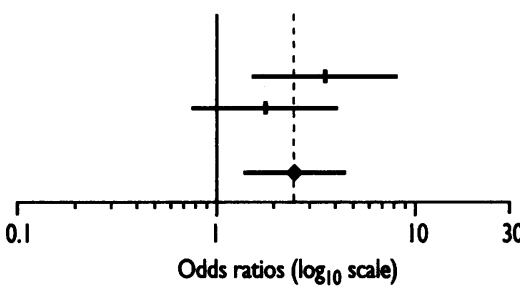

Fig 6-Odds ratios (95\% confidence intervals) for proportion of patients who showed $50 \%$ reduction in frequency of seizures (50\% responders) after add-on treatment with zonisamide likely to cause withdrawal than the one which seemed least likely to cause withdrawal (lamotrigine).

\section{Discussion}

COMPARING EFFICACY OF NEW ANTIEPILEPTIC DRUGS

It is possible to make some broad comparisons of the potency of the new drugs against partial epilepsy from available parallel group data using a measure of the placebo response in these trials as a comparator. Of the patients with refractory partial epilepsy who were randomised to placebo in the parallel studies included in this overview, $0-18 \%$ showed a $50 \%$ reduction in the frequency of seizures, which probably represents a "regression to the mean" phenomenon. ${ }^{29}$ When you compare the point estimate odds ratios for this response gabapentin and lamotrigine seem mildly effective drugs, with odds ratios for $50 \%$ response two to three times that of placebo. It may be that the full dose-response relation of these drugs has not yet been fully explored. Tiagabine seems to have a relatively well defined dose responsiveness, ranging from a mild effect (like that of gabapentin and lamotrigine) at $16 \mathrm{mg}$ a day up to more substantial effects at $56 \mathrm{mg}$ a day. This responsiveness seems to be mimicked by vigabatrin. Topiramate has the best documented dose-response curve, with a clear plateau that helps to define the maximal therapeutic dose at about $600 \mathrm{mg}$ a day.

When we compared the summary estimates of odds ratios for $50 \%$ responders with each drug the $95 \%$ confidence intervals overlapped despite the fact that the antiepileptic drugs with the lowest odds ratios had probably not been tested at their optimal doses. Therefore, we do not have conclusive evidence to support apparent differences in efficacy, and the results of this paper do not allow doctors to make an evidence based choice between these drugs. However, important differences in efficacy may well exist, and this requires further evaluation by direct comparison of drugs in randomised trials. It may be that, by collapsing a continuous variable (change in seizure frequency) to a binary one $(50 \%$ reduction), we reduced the power to detect differences. Further analyses using data for individual patients are planned in the context of a Cochrane Epilepsy Group.

COMPARING EFFICACY OF OLD ANTIEPILEPTIC DRUGS

The standard antiepileptic drugs have been compared in several comparative monotherapy trials. The Veterans Association has performed two of the largest trials. The first of these compared phenobarbitone, carbamazepine, phenytoin, and primidone. ${ }^{7}$ The primary measure of efficacy was retention on treatment: little difference was found between carbamazepine and phenytoin, but both were significantly better than phenobarbitone or primidone, largely because these drugs were significantly less well tolerated. The second study compared carbamazepine and valproate and found no difference in retention rates or the number of patients rendered seizure free, and patients with complex partial seizures had significantly fewer seizures. ${ }^{30}$ Two European studies, the adult ${ }^{31}$ and paediatric $^{32}$ EPITEG studies, also compared carbamazepine and valproate and found no significant differences between these drugs, although confidence intervals were wide. As yet we do not have any clear evidence of differences in efficacy between the standard antiepileptic drugs, but a meta-analysis of monotherapy studies based on data for individual patients is currently under way and may well clarify matters.

There are difficulties in using the results generated in our review to make comparisons with the older and accepted drugs as these have rarely been tested as add-on treatments in placebo controlled trials. The only such study of an older drug that we have been able to find compared valproate $2400 \mathrm{mg}$ a day with placebo. ${ }^{33}$ 
This study generated an odds ratio ( $95 \%$ confidence interval) of 3.33 (1.65 to 6.70 ) for $50 \%$ responders. This result is similar to those generated in our review of new antiepileptic drugs, but again the confidence intervals are wide.

The optimum method of determining future use of new drugs will be by means of studies directly comparing active treatments. Some already exist for lamotrigine: this seems to possess similar efficacy to carbamazepine and phenytoin but has some significant benefits in terms of better tolerability. In one study lamotrigine was shown to be significantly superior to carbamazepine for the important measure of global effectiveness, time to withdrawal from the drug after randomisation. ${ }^{34}$

COMPARING TOLERABILITY OF NEW ANTIEPILEPTIC DRUGS

Some judgments can be made about the relative tolerability of the new antiepileptic drugs. Comparisons of the odds ratios for withdrawal suggest that gabapentin and lamotrigine may be better tolerated than tiagabine, topiramate, vigabatrin, and zonisamide. This is not surprising as the first two drugs have probably not yet been tested at their maximum effective doses. Here again the $95 \%$ confidence intervals for these point estimates overlap, and we have no conclusive evidence of any difference in tolerability. Zonisamide seems to have only moderate efficacy but a relatively high rate for withdrawal and may therefore represent a poor choice for a patient with refractory epilepsy.

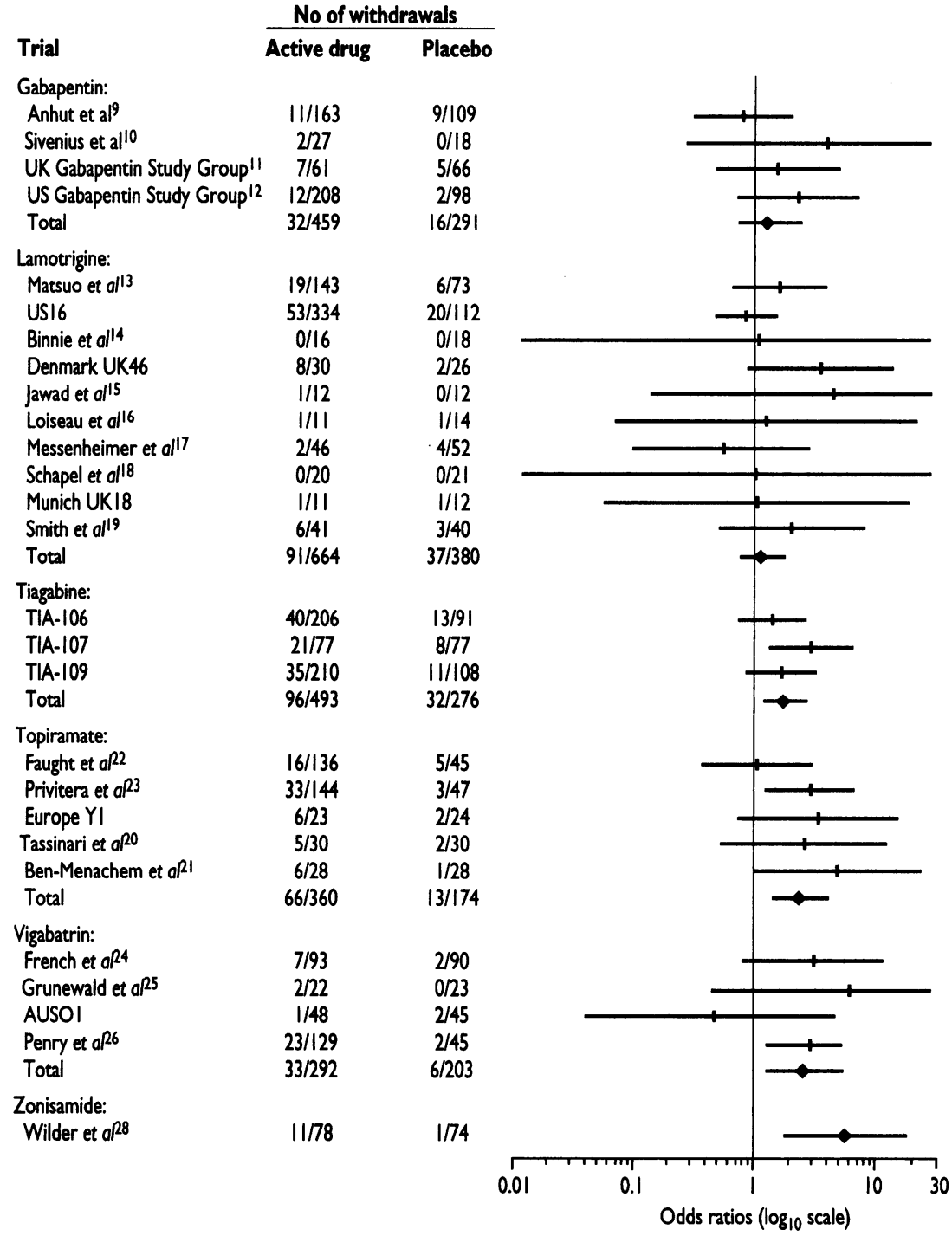

Fig 7 -Odds ratios (95\% confidence intervals) for withdrawal for any reason from add-on treatment with new antiepileptic drugs

\section{Key messages}

- As up to $30 \%$ of patients with epilepsy will be refractory to standard antiepileptic treatments, there is renewed interest in developing new antiepileptic drugs

- At present there is insufficient evidence to guide a choice between these new treatments

- We systematically reviewed randomised placebo controlled studies of supplementary gabapentin, lamotrigine, tiagabine, topiramate, vigabatrin, and zonisamide

- Each drug was significantly better than placebo at preventing seizures, but none was significantly different from the others in terms of efficacy or tolerability, though the confidence intervals were wide

- Randomised trials comparing active treatments are needed to further evaluate these drugs

The side effect profiles of these drugs are likely to differ, but an analysis of the data about side effects from the studies included in this review did not have the power to detect any significant differences. ${ }^{35}$ For a condition such as epilepsy, in which clinical prognostic factors rather than individual treatments determine outcome, it is likely that tolerability will be the important factor that will differentiate between new antiepileptic drugs when comparative monotherapy studies become available.

LIMITATIONS OF OUR CURRENT KNOWLEDGE

Our results cannot be extrapolated to patients with generalised epilepsies, where there is little data. There is clearly a need for studies in such patients. In addition, this review shows the sparsity of information on the new antiepileptic drugs and childhood epilepsies. It is surely important that children and their unique epilepsies are examined in randomised clinical trials, at an earlier stage of drug development than is currently the case. ${ }^{36}$

What do these results tell us about the use of new antiepileptic drugs in our current patient population? With the exception of lamotrigine, there is no evidence to suggest they should be used as monotherapy in newly diagnosed patients as standard, cheaper drugs are highly effective. Despite the fact that we have insufficient evidence to make an evidence based choice between these drugs, doctors still have to choose between them. For patients with refractory epilepsy, who by definition have poor seizure control, drugs with the best apparent evidence of potency would seem the optimal choice (topiramate, vigabatrin, tiagabine). For patients with a history of drug intolerance but adequate seizure control, gabapentin and lamotrigine may be the best option.

We thank the representatives of Parke-Davis, GlaxoWellcome, Novo-Nordisk, Janssen-Cilag, Hoechst Marrion Roussel, and Dianippon for their invaluable help and provision of unpublished data for use in this project.

Funding: AGM is funded by a Wellcome Trust project grant. Conflict of interest: None.

1 Reynolds EH, Shorvon SD, Galbraith AW. Phenytoin for epilepsy: a long term prospective study, assisted by serum level monitoring in previously untreated patients. Epilepsia 1981;22;475.

2 Cockerell OC, Johnson AL, Sander JW, Hart YM, Shorvon SD. Remission of epilepsy: results from the national general practice study of epilepsy. Lancet 1995;346:140-4.

3 Hauser WA, Kurland LT. The epidemiology of epilepsy in Rochester, Minnesota, 1935 through 1967. Epilepsia 1975;16:1-66.

4 Marson AG, Chadwick DW. Comparing antiepileptic drugs. Curr Opin Neurol 1996;9:103-6.

5 Marson AG, Chadwick DW. How easy are randomized controlled trials in epilepsy to find on Medline? The sensitivity and precision of two Medline searches. Epilepsia 1996;37(4):377-80. 
6 Ring HA, Heller AJ, Farr IN, Reynolds EH. Vigabatrin: rational treatment for chronic epilepsy. F Neurol Neurosurg Psychiatry 1990;53:1051-5.

7 Mattson RH, Cramer JA, Collins JF, Smith DB, Delgado-Escueta AV, Browne TR, et al. Comparison of carbamazepine, phenobarbital, phenytoin, and primidone in partial and secondarily generalized tonic-clonic seizures. N Engl f Med 1985;313:145-51.

8 Antiplatelet Trialists' Collaboration. Collaborative overview of randomized trials of antiplatelet therapy. Prevention of death, myocardial infarction, and stroke by prolonged antiplatelet therapy in various categories of patients. BMF 1994;308:81-106.

9 Anhut H, Ashman P, Feuerstein TJ, Sauermann W, Saunders M, Schmid B. Gabapentin (Neurontin) as add-on therapy in patients with partial seizures: a double-blind, placebo-controlled study. The International Gabapentin Study Group. Epilepsia 1994;35:795-801.

10 Sivenius J, Kalviainen R, Ylinen A, Riekkinen P. Double blind study of gabapentin in the treatment of partial seizures. Epilepsia 1991:32:539-42.

gabapen 1990;335:1114-7.

12 US Gabapentin Study Group No 5. Gabapentin as add-on therapy in refractory partial epilepsy: a double-blind, placebo-controlled, parallelgroup study. Neurology 1993;43:2292-8.

3 Matsuo F, Bergen D, Faught E, Messenheimer JA, Dren AT, Rudd GD et al. Placebo-controlled study of the efficacy and safety of lamotrigine in patients with partial seizures. US Lamotrigine Protocol 0.5 Clinical Trial Group. Neurology 1993;43:2284-91

14 Binnie CD, Debets RM, Engelsman M, Meijer JW, Meinardi H, Overweg J, et al. Double blind crossover trial of lamotrigine (Lamictal) as add on therapy in intractable epilepsy. Epilepsy Res 1989;4:222-9.

15 Jawad S, Richens A, Goodwin G, Yuen WC. Controlled trial of lamotrigine (Lamictal) for refractory partial seizures. Epilepsia 1989;30:356-63.

16 Loiseau P, Yuen AW, Duche B, Menager T, Arne Bes MC. A randomised double blind placebo controlled crossover add on trial of lamotrigine in patients with treatment resistant partial seizures. Epilepsy Res 1990;7:13645 .

17 Messenheimer J, Ramsay RE, Willmore LJ, Leroy RF, Zielinski JJ, Mattson $\mathrm{R}$, et al. Lamotrigine therapy for partial seizures: a multicenter, R, et al. Lamotrigine therapy for partial seizures: a multicenter, placebo-controlled, double-bl

18 Schapel GJ, Beran RG, Vajda FJ, Berkovic SF, Mashford ML, Dunagan FM, et al. Double blind, placebo controlled, crossover study of lamotrigine in treatment resistant partial seizures. $f$ Neurol Neurosurg Psychiatry 1993;56:448-53.

19 Smith D, Baker G, Davies G, Dewey M, Chadwick DW. Outcomes of add on treatment with lamotrigine in partial epilepsy. Epilepsia 1993;34:312 22.

20 Tassinari CA, Michelucci R, Chauvel P, Chodiewicz J, Shorvon S, Henriksen $\mathrm{O}$, et al. Double blind placebo controlled trial of topiramate $(600 \mathrm{mg}$ daily) for the treatment of refractory partial epilepsy. Epilepsic 1996;37:763-8

21 Ben-Menachem E, Henriksen O, Dam M, Schmidt D. Double blind placebo controlled trial of topiramate as add-on treatment in parients with refractory partial epilepsy. Epilepsia 1996;36:539-43
22 Faught E, Wilder BJ, Ramsay E, Reife R, Kramer L, Pledger G, et al. Topiramate controlled dose ranging trial in refractory partial epilepsy Topiramate c0n and 600 mo raily dos using 200,400 and 600 mg dally dosages. Neurology $1996,46: 1684-90$.

Privitera M, Fincham R, Renry J, Reife R, Kramer L, Pledger G, et al Topiramate placebo controlled trial in refractory partial epilepsy using 600,800 and $1000 \mathrm{mg}$ daily dosages. Neurology 1996;46:1678-83.

24 French JA, Mosier M, Walker S, Somerville K, Sussman N, the Vigabatrin Protocol 024 Investigative Cohort. A double-blind, placebo controlled study of vigabatrin $3 \mathrm{~g} /$ day in patients with uncontrolled complex partial seizures. Neurology 1996;46:54-61.

25 Grunewald RA, Thompson PJ, Corcoran R, Corden Z, Jackson GD, Duncan JS. Effects of vigabatrin on partial seizures and cognitive function. $f$ Neurol Neurosurg Psychiatry 1994;57:1057-63.

26 Penry JK, Wilder BJ, Sachdeo RC, Vaughan LV, Ahlbrandt RA Sommerville KW, et al. Multicenter dose-response study of vigabatrin in adults with focal (partial) epilepsy [abstract]. Epilepsia 1993;34(suppl 6):67

27 Schmidt D, Jacob R, Loiseau P, Deisenhammer E, Klinger D, Despland A et al. Zonisamide for add on treatment of refractory partial epilepsy: a European double blind trial. Epilepsy Res 1993;15:67-73.

28 Wilder BJ, Ramsay RE, Guterman A. A double-blind multicenter placebo-controlled study of the efficacy and safety of zonisamide in the treatment of complex partial seizures in medically refractory patients. Internal report of the Dianippon Pharmaceutical Co. 1986

29 Spilker B, Segreti A. Validation of the phenomenon of regression of seizure frequency in epilepsy. Epilepsia 1984;25:443-9.

30 Mattson RH, Cramer JA, Collins JF. A comparison of valproate with carbamazepine for the treatment of complex partial seizures and secondarily generalized tonic clonic seizures in adults. The Department of Veterans Affairs Epilepsy Cooperative Study No 264 Group. $N$ Engl $f$ Med 1992;327:765-71.

31 Richens A, Davidson DL, Cartlidge NE, Easter DJ. A multicentre comparative trial of sodium valproate and carbamazepine in adult onset epilepsy. Adult EPITEG Collaborative Group. $₹$ Neurol Neurosurg Psychiatry 1994;57:682-7.

32 Verity CM, Hosking G, Easter DJ. A multicentre comparative trial of sodium valproate and carbamazepine in paediatric epilepsy. The Paediatric EPITEG Collaborative Group. Dev Med Child Neurol 1995;37:97-108.

33 Willmore JL, Shu V, Wallin B, the M88-194 Study Group. Efficacy and safety of add-on divalproex sodium in the treatment of complex partial eizures.

34 Brodie MJ, Richens A, Yuen AWC. Double-blind comparison of amotrigine and carbamazepine in newly diagnosed epilepsy. Lancer 1995;345:476-9.

35 Chadwick D, Marson AG, Kadir ZA. The clinical use of new antiepileptic drugs: an overview of safety and efficacy. Epilepsia (in press).

36 Commission on Antiepileptic Drugs of the International League Against Epilepsy. Guidelines for antiepileptic drug trials in children. Epilepsia 1994;35:94-100

(Accepted 19 September 1996)

\title{
Intrauterine growth pattern and risk of childhood onset insulin dependent (type I) diabetes: population based case-control study
}

\author{
Gisela Dahlquist, Sara Sandberg Bennich, Bengt Källén
}

\section{Abstract}

Objective-To investigate whether prenatal growth affects the risk of development of childhood onset insulin dependent (type I) diabetes mellitus.

Design-Population based case-control study.

Setting-Data from a nationwide childhood diabetes case register were linked with data from the nationwide Swedish Medical Birth Registry.

Subjects-Data from a total of 4584 diabetic children born after 1973 and diagnosed with diabetes from 1978 to 1992 were studied. For each child with insulin dependent diabetes three control children were randomly selected from among all infants born in the same year and at the same hospital as the proband.

Main outcome measures-Birth weight, gestation, maternal age and parity, number of previous spontaneous abortions, and sex specific birth weight by gestational week expressed as multiples of the standard deviation (SD).

Results-There was a clear trend in the odds ratio for childhood onset diabetes according to SD of birth weight. The odds ratio ( $95 \%$ confidence interval) for small for gestational age after stratification for maternal age, parity, smoking habits, and maternal diabetes was $0.81(0.65$ to 0.99$)$ and for large for gestational age after similar stratification was 1.20 (1.02 to 1.42$)$.

Conclusions-Intrauterine conditions that affect prenatal growth seem also to affect the risk of development of childhood diabetes in the way previously described for postnatal growth: a poor growth decreases and an excess growth increases the risk. The mechanism for this association is unclear.

\section{Introduction}

There is evidence that both future immune reactivity ${ }^{1}$ and carbohydrate metabolism ${ }^{2}$ can be affected by the intrauterine environment of the fetus. Both types of associations may be relevant for the pathogenesis of insulin dependent (type I) childhood onset diabetes. In a previous study we reported on several perinatal risk determinants for insulin dependent diabetes ${ }^{3}$ among which we found a significant effect of short gestation but no effect of birth weight or body length. We have now studied the importance of disturbances in intrauterine growth on the risk for childhood onset insulin dependent diabetes in greater detail, using extended material and the recently published normal growth chart for Swedish children. ${ }^{4}$ 